Hydrogels: Design, Synthesis \& Application in Drug Delivery \& Regenerative Medicine. Edited by Thakur Raghu Raj Singh, Garry Laverty and Ryan Donnelly 2017 SCIENCE PUBLISHERS

(An Imprint of CRC Press/ Taylor \& Francis Group)

\title{
Silk Hydrogels for Drug and Cell Delivery
}

\author{
F. Philipp Seib
}

Strathclyde Institute of Pharmacy and Biomedical Sciences, University of Strathclyde, 161 Cathedral Street, Glasgow, G4 0RE, UK

F. Philipp Seib; Tel: +44 141-548-2510; Fax: +44 141-552-2562; emails: philipp.seib@strath.ac.uk or philipp.seib@SeibLab.com 
Hydrogels: Design, Synthesis \& Application in Drug Delivery \& Regenerative Medicine. Edited by Thakur Raghu Raj Singh, Garry Laverty and Ryan Donnelly 2017 SCIENCE PUBLISHERS (An Imprint of CRC Press/ Taylor \& Francis Group)

\section{Introduction}

Silk has fascinated humans since ancient times; silk fibres have been used in textiles for more than 5,000 years and for many centuries as a suturing material (Lubec, Holbaubek et al. 1993, Omenetto and Kaplan 2010). The remarkable strength and toughness of silk stems from its evolution as a structural engineering material in nature (Vollrath and Porter 2009, Buehler 2013).

Silk is a sustainable and ecologically benign biopolymer that can be manufactured using green processes (Vollrath and Porter 2009). Over the past 25 years, we have seen a tremendous development of both bottom-up and top-down approaches for the generation of silk biopolymers. Specifically, reverse engineering of silk cocoons and the advent of recombinant technologies have been paramount for a better understanding of silks (Chung, Kim et al. 2012, Tokareva, Jacobsen et al. 2014). For example, molecular simulation studies (Buehler 2013), coupled with dedicated mechanical testing of recombinant and natural silks (Vollrath and Porter 2009), have increased our appreciation of the critical importance of silk's hierarchal structure by which it serves its function (e.g. protects the developing moth in the silk cocoons and catches spider's prey 
Hydrogels: Design, Synthesis \& Application in Drug Delivery \& Regenerative Medicine. Edited by Thakur Raghu Raj Singh, Garry Laverty and Ryan Donnelly

2017 SCIENCE PUBLISHERS

(An Imprint of CRC Press/ Taylor \& Francis Group)

in orb-webs) (Omenetto and Kaplan 2010). Thus, natural silk fibres can serve as blueprints for novel designer polymers.

Today, silk's remarkable physical properties have supported high-end applications, including its use in bulletproof vests (Gatesy, Hayashi et al. 2001), parachute cords (Kluge, Rabotyagova et al. 2008), composite materials for the aviation industry (Hardy and Scheibel 2009), photonics (Omenetto and Kaplan 2008) and electronics (Kim, Viventi et al. 2010). The medical use of silk dates back to its use as a suture material; here the unique physical properties, handling and biocompatibility of silk fibres have been critical for its continued success, as well as for its approval by the Food and Drug Administration (FDA) as a biopolymer for use in humans. However, the medical applications of silk that have emerged over the past decade go beyond its traditional load-bearing applications (Altman, Diaz et al. 2003, Omenetto and Kaplan 2010). In this chapter, we examine the role of silk in drug and cell delivery applications, with specific reference to silk hydrogels, and we highlight emerging trends, opportunities and challenges, as well as provide a sound background on silk biopolymers for the silk novice.

\section{Silk Structure-Function Relationships}

For the purpose of this chapter, we use the term silk to refer to protein-based fibre-forming materials spun by living organisms. Spiders and silkworms are the most prominent organisms associated with silk production, although silks are made by many arthropod taxa (Vollrath and Porter 2009, Porter, Guan et al. 2013). Furthermore, spiders make more than one type of silk. For example, the common European garden spider, Araneus diadematusor, and the golden silk spider, Nephila clavipes, spin seven different silks from seven sets of different silk glands (Vollrath 
Hydrogels: Design, Synthesis \& Application in Drug Delivery \& Regenerative Medicine. Edited by Thakur Raghu Raj Singh, Garry Laverty and Ryan Donnelly

2017 SCIENCE PUBLISHERS

(An Imprint of CRC Press/ Taylor \& Francis Group)

1992); these silks are often used in combination simultaneously to fine tune the overall fibre composition and subsequent performance. Nonetheless, the silks used for drug delivery applications are typically those produced by the silkworm, Bombyx mori, or recombinant versions of spider silks (Yucel, Lovett et al. 2014). Where appropriate, we distinguish between silkworm silk (fibroin) from the cocoons of B. mori and spider silks. We also differentiate silk materials that are reverse engineered native proteins from those generated in heterologous hosts via genetic engineering. When not specifically stated, we refer to silkworm silk because $B$. mori silk is most commonly used due to its abundance (Seib and Kaplan 2013). The hierarchal structure of silk enables this biopolymer to serve specific functions (Fig. 1a, b), including tailored drug release and payload protection. The following section details silk structure with specific reference to drug delivery.

\section{Bombyx mori Silk}

The B. mori silk heavy chain consists predominantly of five amino acids: $45.9 \%$ glycine $(\mathrm{G})$, $30.3 \%$ alanine $(\mathrm{A}), 12.1 \%$ serine $(\mathrm{S}), 5.3 \%$ tyrosine $(\mathrm{Y})$, and $1.8 \%$ valine $(\mathrm{V})$ and only $4.6 \%$ of the other 15 amino acid types (Zhou, Confalonieri et al. 2001). B. mori silk is a very large (2.3 $\mathrm{MDa}$ ) protein that is made up of a heavy chain (approximately $350 \mathrm{kDa}$ ) (Zhou, Confalonieri et al. 2000) and a light chain (approximately 26kDa) (Yamaguchi, Kikuchi et al. 1989) that are held together by a single disulphide bond at the C terminus (Tanaka, Kajiyama et al. 1999) (Fig. 1b); this disulphide linkage is critically important for the successful secretion of silk from the silk gland. The 2.3 MDa elementary silk unit is composed of six sets of disulphide-linked heavy and light chain heterodimers that assemble and are physically complexed by one molecule of fibrihexamerin (P25, approximately 25kDa). Fibrihexamerin has $N$-linked high mannose type oligosaccharide chains that facilitate the physical interaction with the silk heavy chain (Inoue, 
Hydrogels: Design, Synthesis \& Application in Drug Delivery \& Regenerative Medicine. Edited by Thakur Raghu Raj Singh, Garry Laverty and Ryan Donnelly 2017 SCIENCE PUBLISHERS (An Imprint of CRC Press/ Taylor \& Francis Group)

Tanaka et al. 2000, Inoue, Tanaka et al. 2004). The 6:6:1 molar ratio of heavy chain, light chain and fibrihexamerin that makes up the silk elementary unit ensures solubility during transport, both intracellularly and in the silk gland (Zhou, Confalonieri et al. 2001). However, the heavy chain is of particular importance for the overall physical performance of silk and is believed to have a critical influence on the ability of silk to serve as a biopolymer for drug delivery as well as to assume various forms, including hydrogels (Seib and Kaplan 2013). 
Hydrogels: Design, Synthesis \& Application in Drug Delivery \& Regenerative Medicine. Edited by Thakur Raghu Raj Singh, Garry Laverty and Ryan Donnelly 2017 SCIENCE PUBLISHERS

(An Imprint of CRC Press/ Taylor \& Francis Group)

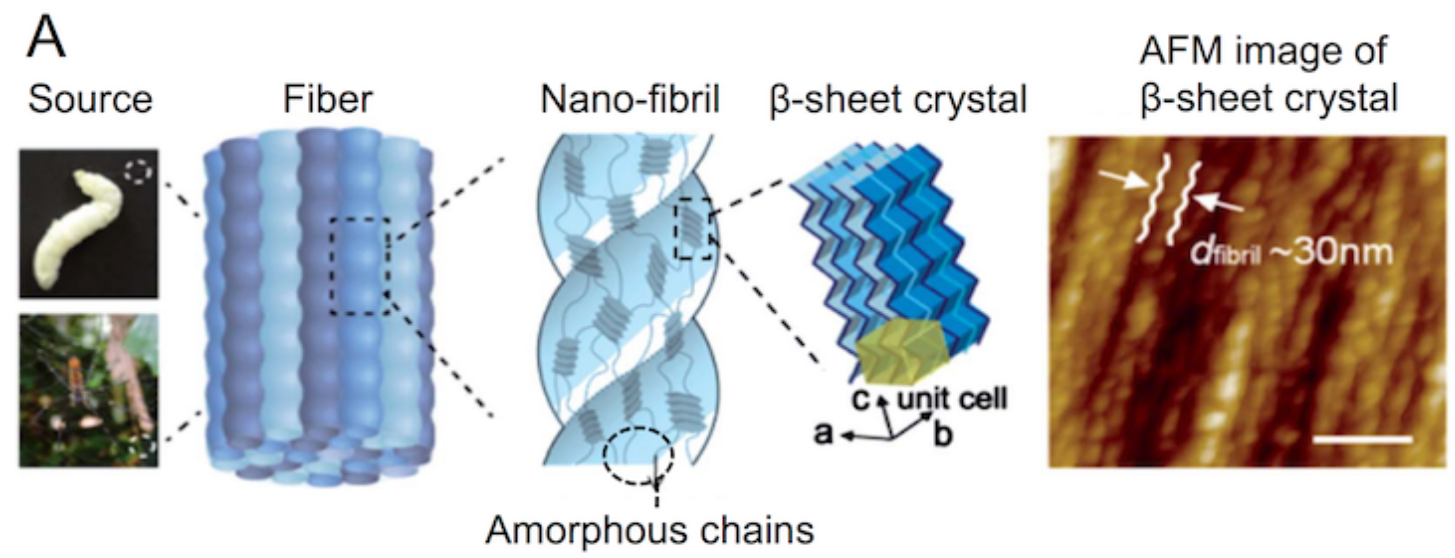

B

N-terminus

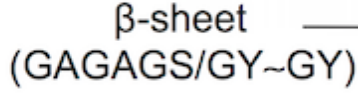

C

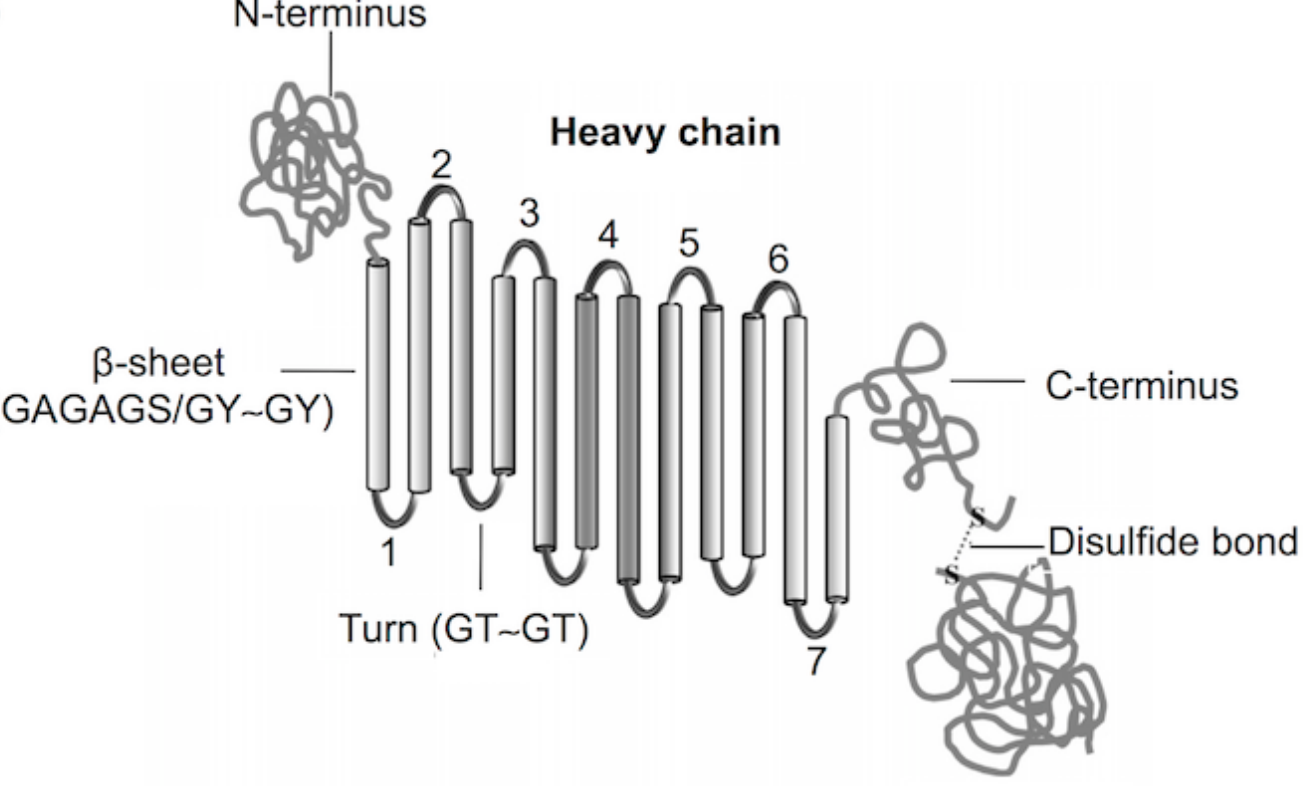

(i)

(ii)

(iii)
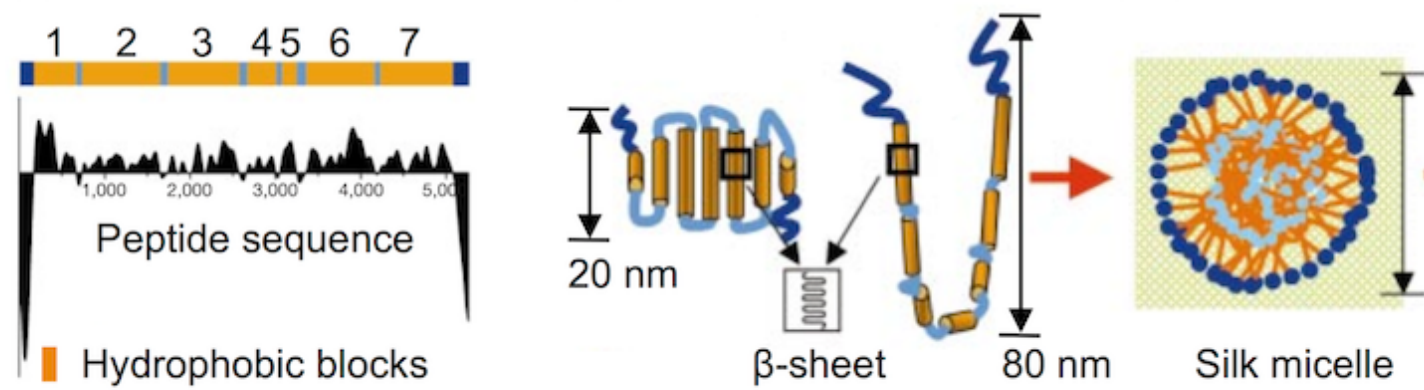

Silk micelle

Hydrophophilic blocks (non-repetitive) $(100-200 \mathrm{~nm})$ 
Hydrogels: Design, Synthesis \& Application in Drug Delivery \& Regenerative Medicine. Edited by Thakur Raghu Raj Singh, Garry Laverty and Ryan Donnelly

2017 SCIENCE PUBLISHERS

(An Imprint of CRC Press/ Taylor \& Francis Group)

Figure 1 Overview of the different scales and hierarchical structure of silkworm and spider dragline silk fibres. (A) Both spider and silkworm silks are similar and are composed of numerous interlocking nano-fibrils. The $\beta$-sheet crystals stabilise the silk fibril and provides strength while and the amorphous segments within these nano-fibrils endow silk with elasticity. Each $\beta$-sheet crystal is composed of stacked sheets that are stabilised by hydrogen bonding between each sheet. The yellow box indicates the unit cell of a single $\beta$-sheet crystal. Atomic force microscopy image of the nano-fibrillar structure in B. mori silk (scale bar $100 \mathrm{~nm}$ ). (B) 2 dimensional schematic of B. mori silk. Numbers are aligned with the hydrophobicity pattern. (C) Model of B. mori heavy chain folding and micelle formation. (i) Hydrophobicity pattern of the heavy chain with (ii) possible chain folding and (iii) micelle assembly of silk in water. Micelle formation is based on the block copolymer configuration of silk with internal smaller hydrophilic domains to promote solubility in water and larger chain terminal hydrophilic blocks in contact with the continuous water phase. (Panel A reproduced with permission from (Xu, Gong et al. 2014), panel B from (Ha, Gracz et al. 2005) and panel C modified from (Jin and Kaplan 2003)).

The primary sequence of $B$. mori silk heavy chain resembles that of an amphiphilic block co-polymer, with hydrophobic blocks alternating with hydrophilic ones (Ha, Gracz et al. 2005, Yucel, Lovett et al. 2014) (Fig. 1c). This block co-polymer is flanked by hydrophilic C- and Ntermini composed of completely non-repeating amino acid residues. Specifically, the heavy chain has 12 long hydrophobic, "crystallisable" blocks that are interspaced by 11 nearly identical, less repetitive and more hydrophilic "amorphous" blocks that have an anionic character; the result is an overall silk isoelectric point of approximately 4 (Fig. 1b). The crystallisable blocks are made 
Hydrogels: Design, Synthesis \& Application in Drug Delivery \& Regenerative Medicine. Edited by Thakur Raghu Raj Singh, Garry Laverty and Ryan Donnelly

2017 SCIENCE PUBLISHERS

(An Imprint of CRC Press/ Taylor \& Francis Group)

up of GX repeats and account for $94 \%$ of the silk heavy chain sequence (Zhou, Confalonieri et al. 2001) (Fig. 1c). The hexa-amino acid sequence, GAGAGS, is the main component of the typical silk $\beta$-sheet crystal and is interspersed with small, irregular GAAS tetrapeptides and 60 residues containing GY (GY GY) sequences (Ha, Gracz et al. 2005). These GAGAGS/GY GY crystalline building blocks are usually composed of glycine (G), alanine (A), serine (S), and tyrosine $(\mathrm{Y})$, while valine $(\mathrm{V})$, threonine $(\mathrm{T})$, isoleucine $(\mathrm{I})$ and phenylalanine $(\mathrm{F})$ are not major residue types but sometimes appear in GAGAGS/GY GY blocks (Ha, Gracz et al. 2005).

One silk heavy chain has 12 intramolecular antiparallel $\beta$-strands and 11 amorphous regions. The amorphous regions typically consist of 31 amino acid with sequence irregularity (GT GT), but always contain proline residues that can act as major factors for changing the backbone direction (Fig. 1b). The crystalline and amorphous blocks in the silk heavy chain contribute significantly to the fibre's physical properties (Ha, Gracz et al. 2005). In particular, sequence motifs, such as poly alanine-glycine (polyAG) and polyalanine (polyA) ( $\beta$ sheetforming), GXX (31-helix), GXG (stiffness), and GPGXX ( $\beta$ spiral), are key components, and their relative positioning and arrangement are intimately tied to the overall material properties (Omenetto and Kaplan 2010).

Manipulation of the crystal form and content allow fine-tuning of the physical properties of silk and subsequently affect its performance as a drug delivery system (Yucel, Lovett et al. 2014). In aqueous solutions, the crystallisable domains of silk form $\beta$-strands and 3 -stranded $\beta$-sheets, which are stabilised through hydrogen bonding; the increasing interaction of the hydrophobic blocks drives $\beta$-sheet formation through lateral and facial packing (Ha, Gracz et al. 2005, Yucel, 
Hydrogels: Design, Synthesis \& Application in Drug Delivery \& Regenerative Medicine. Edited by Thakur Raghu Raj Singh, Garry Laverty and Ryan Donnelly

2017 SCIENCE PUBLISHERS

(An Imprint of CRC Press/ Taylor \& Francis Group)

Lovett et al. 2014). The hydrophobic, crystallisable blocks are interspaced by hydrophilic blocks and capped by $\mathrm{N}$ - and $\mathrm{C}$-terminal sequences; this block copolymer arrangement drives the formation of 100-200 $\mathrm{nm}$ sized spherical micellar structures that contain a hydrophobic core of crystalline/amorphous domains, and a hydrophilic shell of the terminal domains (Jin and Kaplan 2003) (Fig. 1c). These micelles remain loosely assembled, and the assembly process is reversible (Lu, Zhu et al. 2012).

Under aqueous conditions that mimic the B. mori silk gland microenvironment, these nanometre-sized micelles assemble into larger microscale globules $(0.8-15 \mu \mathrm{m})$ and gel-like states, while maintaining solubility (Werner and Meinel 2015). However, a number of external triggers, such as stretching, shearing, electromagnetic fields, solution concentration, $\mathrm{pH}$ and ionic strength cause irreversible physical intermicellar and inter globular crosslinking (Werner and Meinel 2015). The resulting silk networks have an increased $\beta$-sheet content and are formed though the self-assembly process detailed above, thereby eliminating the need for use of any harsh chemicals or crosslinkers. The self-assembly of silk into these globular micelles is exploited when generating silk nanoparticles (Werner and Meinel 2015); for example, the addition of an aqueous silk solution to a miscible organic solvent (e.g. acetone) results in nanoprecipitation and formation of nanoparticles (Seib, Jones et al. 2013) that are characterised by high crystallinity in the densely packed core (reviewed in (Zhao, Li et al. 2015)).

The silk heavy chain shows crystalline polymorphism with three predominant forms, namely silk I, II and III (Marsh, Corey et al. 1955, Valluzzi, Gido et al. 1999, Asakura, Suzuki et al. 2013). Silk I is the metastable silk form present in silk solutions (Asakura, Suzuki et al. 2013); 
Hydrogels: Design, Synthesis \& Application in Drug Delivery \& Regenerative Medicine. Edited by Thakur Raghu Raj Singh, Garry Laverty and Ryan Donnelly

2017 SCIENCE PUBLISHERS

(An Imprint of CRC Press/ Taylor \& Francis Group)

it is characterised by intra- and intermolecular bonding repeats of type II and a $\beta$-turn structure that result in a more compact silk conformation than seen with silk II (Asakura, Suzuki et al. 2013). Silk II represents the antiparallel $\beta$-sheets of crystallised silk that are found in spun silk fibres (Marsh, Corey et al. 1955, Asakura, Suzuki et al. 2013); silk III forms a 3-fold extended helix at a water-air interface (Valluzzi, Gido et al. 1999). Silk-based drug delivery devices are typically made up of a mixture of $\beta$-sheets, $\beta$-turns, helices and random coils, although the extent of each can be fined tuned, and this is known to influence drug release (Seib and Kaplan 2013, Yucel, Lovett et al. 2014).

\section{Spider Silks}

To date, B. mori silk cocoons are the most commonly used silk source for the development of drug delivery systems because $B$. mori silk can be readily mass-produced using sericultures (Seib and Kaplan 2013). In contrast, spiders cannot be farmed; therefore, spider silks are typically obtained by expression using a heterologous host via genetic engineering (Chung, Kim et al. 2012). Dragline spider silk is the most commonly studied spider silk because this silk is used to build the frames and radii of orb webs, as well as serving as the spider's safety line (Vollrath and Porter 2009, Porter, Guan et al. 2013). This silk is thus endowed with an exceptionally high tensile strength and elasticity to serve its function. Dragline silk is composed of two major proteins: the major ampullate spidroin 1 and 2 (MaSp1 and MaSp2) in silk from the Gold Orb weaver spider (Nephila clavipes) and Araneus diadematus fibroin 3 and 4 (ADF-3 and -4) in silk from the common European garden spider (Scheibel 2004). The small peptide motifs of spider silks can be grouped into four major categories: (i) crystalline $\beta$-sheet rich poly $(\mathrm{A}) / \operatorname{poly}(\mathrm{GA})$ motifs (ii) helix forming GGX repeats, (iii) an elastic $\beta$-turn-like proline-rich region, composed 
Hydrogels: Design, Synthesis \& Application in Drug Delivery \& Regenerative Medicine. Edited by Thakur Raghu Raj Singh, Garry Laverty and Ryan Donnelly

2017 SCIENCE PUBLISHERS

(An Imprint of CRC Press/ Taylor \& Francis Group)

of multiple GPGXX motifs (where $\mathrm{P}$ is proline and $\mathrm{X}$ is mostly glutamine) and (iv) a spacer region with currently unknown functions (Tokareva, Jacobsen et al. 2014).

Across all araneid, the dragline spider silks have a very high molecular weight (reviewed in (Scheibel 2004). For example, MaSP 1 and 2 silk proteins possess similar motifs and are approximately 3,500 amino acids long, resulting in a protein with a molecular mass of 250-350 kDa (Sponner, Schlott et al. 2005, Ayoub, Garb et al. 2007). As is the case with B. mori silk, spider silks contain long repetitive sequences that are rich in glycine and alanine and are flanked at the $\mathrm{C}$ and $\mathrm{N}$ termini by non-repeating amino acid sequences approximately 100 amino acids in length (Ayoub, Garb et al. 2007); these non-repeating sequences are thought to orchestrate the self-assembly process during spinning (Jin and Kaplan 2003, Exler, Hummerich et al. 2007, Askarieh, Hedhammar et al. 2010, Hagn, Eisoldt et al. 2010). Analogous to the situation with $B$. mori silk, the polyalanine residues give high tensile strength to the silk fibre. These hydrophobic polyalanine blocks are typically made up of six to nine alanines and several polyalanine chains are required to form the crystalline $\beta$-sheet stacks. The glycine-rich motifs, such as GGX or GPGXX, adopt flexible helical structures and act as molecular springs interspersed among the crystalline regions to provide elasticity to the silk thread (Chung, Kim et al. 2012, Tokareva, Jacobsen et al. 2014).

Unlike B. mori, which can be raised as sericultures, spiders are more challenging to raise for silk production and are rarely used as a primary silk source. The large size of naturally occurring spider silks and the highly repetitive nature of these proteins also pose challenges during expression in heterologous hosts, in part due to the limits of the glycyl-tRNA pools in the 
Hydrogels: Design, Synthesis \& Application in Drug Delivery \& Regenerative Medicine. Edited by Thakur Raghu Raj Singh, Garry Laverty and Ryan Donnelly

2017 SCIENCE PUBLISHERS

(An Imprint of CRC Press/ Taylor \& Francis Group)

expression host (Seib and Kaplan 2013). This has recently been overcome by the use of metabolically engineered E. coli, where recombinantly expressed silk matched the protein made by spiders with respect to its molecular weight and mechanical properties (Xia, Qian et al. 2010). However, most studies that have explored spider silks for drug delivery applications have used the ADF-4 and MaSp1 sequences to generate spider silk-inspired biopolymers that are tens of $\mathrm{kDa}$ in size. For example, eADF4-(C16) consists of 16 repeats of module $\mathrm{C}$ (GSSAAAAAAAASGPGGYG PENQGPSGPGGYGPGGP), which mimics the repetitive core sequence of ADF4 of the European garden spider and yields a biopolymer $48 \mathrm{kDa}$ in size. This eADF4-(C16) biopolymer has been explored for various drug delivery applications, including silk nanoparticle (Lammel, Schwab et al. 2011) and hydrogels (Schacht, Jungst et al. 2015) for drug delivery. Recombinant silks have been the foundation for a number of spin out companies, including eADF4-(C16) which is central to AMSilk's commercial portfolio which now includes silk-based fibres, coatings and cosmetics.

In addition to ADF4, the Nephila clavipes MaSp1 silk consensus repeat SGRGGLGGQGAGAAAAAGGAGQGGYGGLGSQGT has been widely studied for the generation of silk (nano)particles, fibres, hydrogels and hybrid materials for both tissue engineering applications and drug delivery (Tokareva, Jacobsen et al. 2014). The isolation of spider silk from the expression host will not be reviewed here (see excellent reviews; for example, (Scheibel 2004, Chung, Kim et al. 2012, Ebrahimi, Tokareva et al.). However, the extraction procedure used to isolate silk from cocoons has a significant impact on the final biopolymer properties, so this will be briefly reviewed. 
Hydrogels: Design, Synthesis \& Application in Drug Delivery \& Regenerative Medicine. Edited by Thakur Raghu Raj Singh, Garry Laverty and Ryan Donnelly

2017 SCIENCE PUBLISHERS

(An Imprint of CRC Press/ Taylor \& Francis Group)

\section{Reverse Engineering Silk Cocoons}

Silkworm fibres consist of two types of proteins: silk fibroin (commonly referred to as silk) and sericins. Sericin is used by the worm during the spinning process to "glue" silk fibres together. Sericins are commonly removed when processing $B$. mori cocoons, as they are thought to induce an inflammatory response, especially in combination with silk (reviewed in (Altman, Diaz et al. 2003)). Typical strategies for sericin removal include boiling (i.e. degumming) the cocoons in an aqueous alkaline solution (e.g. sodium carbonate) (Rockwood, Preda et al. 2011). While most studies report degumming times ranging from 20 to 60 minutes, a short 5 minute degumming process is usually sufficient to remove the sericin and minimise degradation of the silk. Silk is degraded into smaller fragments during prolonged boiling, which particularly affects the silk light chain, the disulphide bond between the light and heavy chain, and the amorphous regions in the silk heavy chain (Wray, Hu et al. 2011). After degumming, the extracted silk fibres can be used to generate yarns, sutures or woven fabrics. However, the generation of new silk material formats, such as silk hydrogels, typically requires that the extracted silk fibre be reverse engineered into an aqueous silk solution that resembles the silk dope found the silk worm's gland. Therefore, the silk fibre is dismantled with the use of chaotropic agents at elevated temperatures (e.g. 9.3 M LiBr at $60^{\circ} \mathrm{C}$ for up to 4 hours) to disrupt hydrogen bonding and unfold the silk crystalline domains.

The resulting silk solution is dialysed extensively against water to yield an aqueous silk solution of typically $6 \% \mathrm{w} / \mathrm{v}$. A more concentrated silk solution can be readily obtained by dialysing silk against a $10 \% \mathrm{w} / \mathrm{v}$ polyethylene glycol solution, which withdraws water from the silk preparation. The aqueous silk solution can be processed into various material formats, such as films, fibres, scaffolds, micro- and nanoparticles, as well as hydrogels (Rockwood, Preda et al. 
Hydrogels: Design, Synthesis \& Application in Drug Delivery \& Regenerative Medicine. Edited by Thakur Raghu Raj Singh, Garry Laverty and Ryan Donnelly 2017 SCIENCE PUBLISHERS (An Imprint of CRC Press/ Taylor \& Francis Group)

2011) (Fig. 2). Irrespective of the silk format, the material needs to be suited for its intended use. In the following section, we will examine the rationale for using the silk biopolymer for drug and cell delivery.

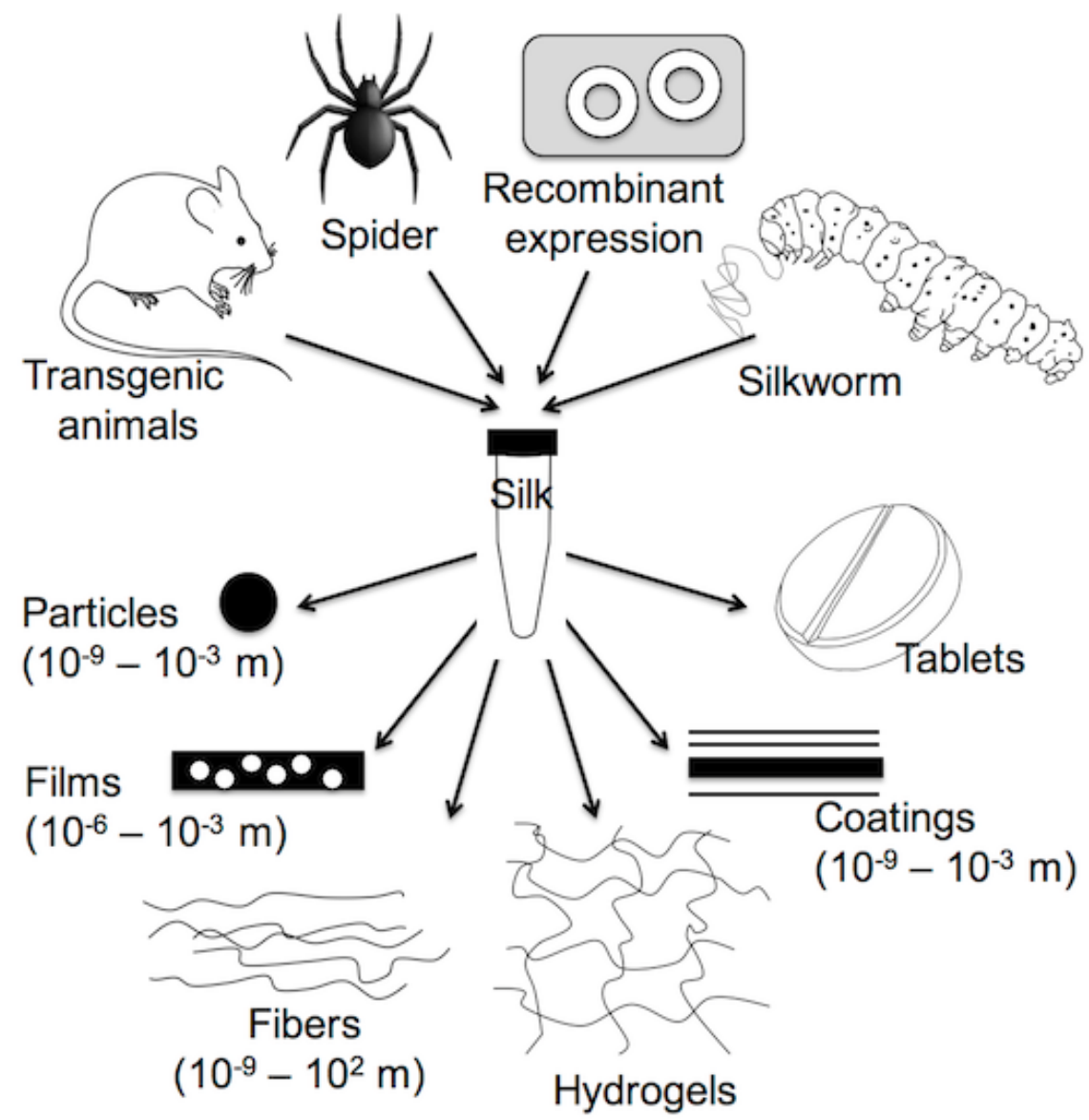

Figure 2 Diagram of silk sources and silk formats. Numbers in parentheses refer to the approximate sizes of these materials; diameters or thicknesses in the case of particles and films/coatings, respectively (reproduced with permission from (Seib and Kaplan 2013)) 
Hydrogels: Design, Synthesis \& Application in Drug Delivery \& Regenerative Medicine. Edited by Thakur Raghu Raj Singh, Garry Laverty and Ryan Donnelly

2017 SCIENCE PUBLISHERS

(An Imprint of CRC Press/ Taylor \& Francis Group)

\section{Rationale for Using Silk for Drug and Cell Delivery}

A number principal attributes are typically cited in support of using silk for cell and drug delivery, including (i) biocompatibility, (ii) biodegradability, (iii) mild processing conditions, (iv) protection of the payload and (v) approved use in humans. Silk fibres are United States of America Food and Drug Administration (FDA) and European Medicines Authority (EMA) approved biomaterials for use in humans as medical sutures; silk-based surgical meshes have also received FDA/EMA approval. These meshes have been developed by Serica Technologies, Inc. Medford MA, USA (subsequently acquired in 2010 by Allergan, Inc.) using technology originally developed by David Kaplan and co-workers at Tufts University, MA, USA. Data from two clinical trials with these surgical meshes have been encouraging, with high levels of investigator and patient satisfaction scores and no adverse reactions due to the silk mesh (De Vita, Buccheri et al. 2014, Fine, Lehfeldt et al. 2015). Early phase trials are currently ongoing to test BioShield-S1 silk coatings of silicone breast implants to improve host-tissue responses [based on eADF4(C16) spider silks manufactured by AMSilk, Munich, Germany]; these clinical studies were preceded by successful in vivo studies that showed no acute systemic toxicity and immunogenicity with eADF4(C16), as well as a significant reduction in capsule formation with the silk-coated silicon implants (Zeplin, Maksimovikj et al. 2014). In particular, the successful track record of silk sutures for use in humans has served as the launching platform for the development of silk-based materials for biomedical applications, including cell and drug delivery.

\section{Biocompatibility}

Nonetheless, the generic use of the term "biocompatibility" to describe silks is potentially misleading. In particular, the notion that any natural material automatically qualifies as 
Hydrogels: Design, Synthesis \& Application in Drug Delivery \& Regenerative Medicine. Edited by Thakur Raghu Raj Singh, Garry Laverty and Ryan Donnelly

2017 SCIENCE PUBLISHERS

(An Imprint of CRC Press/ Taylor \& Francis Group)

biocompatible is widespread but misleading, with potentially disastrous consequences. For example, some of the most toxic compounds known to man are of natural origin (e.g. botulinum toxin). When used clinically and for aesthetic purposes, both the dose and route of administration are critical for safe use. Therefore, all (bio)materials need careful assessment prior to their in vivo use. The biocompatibility definition by David Williams "refers to the ability to perform as a substrate that will support the appropriate cellular activity, including the facilitation of molecular and mechanical signalling systems, in order to optimise tissue regeneration, without eliciting any undesirable local or systemic responses in the eventual host" (Williams 2008). Although silk has a proven track record in humans as a suture material, context specific biocompatibility assessment is still required when silk is being used beyond its licensed applications. For example, silk has been proposed for various vascular tissue engineering applications, but without first undergoing rigorous haematocompatibility assessment. We have assessed the blood compatibility of silk and were able to demonstrate a low haemostasis activity but an inflammatory response that was in part dependent on the processing history of the silk (Seib, Maitz et al. 2012, Seib, Herklotz et al. 2014).

\section{Silk Biocompatibility}

In vivo studies in rats indicated that silk films implanted intramuscularly induced a mild inflammatory response, appearing in the form of fibroblasts, few new blood vessels and macrophages at the implant-host interface. This type of tissue response was more noticeable for polylactide and collagen films at 6 weeks post implantation than for silk films (Meinel, Hofmann et al. 2005). The silk scaffolds also showed different in vivo degradation behaviour depending on whether they were generated by water- or solvent-based processing. For example, water-based 
Hydrogels: Design, Synthesis \& Application in Drug Delivery \& Regenerative Medicine. Edited by Thakur Raghu Raj Singh, Garry Laverty and Ryan Donnelly

2017 SCIENCE PUBLISHERS

(An Imprint of CRC Press/ Taylor \& Francis Group)

silk scaffolds with large pore sizes $(850-1,000 \mu \mathrm{m})$ were completely degraded and resorbed within 6 months, while solvent-based silk scaffolds with a similar pore size showed significantly less degradation over the same time course, with residual material still present one year after implantation. Throughout the study, the animals showed no visible signs of any adverse response. The low host immune response towards the implant was inferred by comparing mRNA expression of various markers, including interferon- $\gamma$, tumour necrosis factor- $\alpha$ and interleukins, from the retrieved scaffolds and control tissues (Wang, Rudym et al. 2008). The results indicated that the macrophages recruited towards the silk were the main contributors to silk degradation, because only scaffolds that allowed cell infiltration showed any substantial degradation over the study period (Wang, Rudym et al. 2008). Silk has been reported to induce a transient and mild foreign body response that activates the complement system, but this response typically subsides within 14 days and does not progress to a chronic inflammatory response (Thurber, Omenetto et al. 2015).

All biomaterials derived from a non-autologous source will elicit a foreign body response following implantation in vivo, albeit to varying degrees (Altman, Diaz et al. 2003). Historically, adverse reactions reported for silk sutures can be largely attributed to the use of virgin silk fibres that contained contaminating sericin, as this causes an allergic reaction, or to the use of braided silk fibres that were coated with waxes (commonly referred to as black braided silk) (Altman, Diaz et al. 2003). Silk fibroin elicits a foreign body response following implantation in vivo (Thurber, Omenetto et al. 2015), but this response is comparable to that elicited by the most popular synthetic materials in use today as biomaterials [e.g. poly(lactic-co-glycolic acid), polycaprolactone, polylactic acid]. 
Hydrogels: Design, Synthesis \& Application in Drug Delivery \& Regenerative Medicine. Edited by Thakur Raghu Raj Singh, Garry Laverty and Ryan Donnelly 2017 SCIENCE PUBLISHERS (An Imprint of CRC Press/ Taylor \& Francis Group)

The intensity of the biological response also depends on the implantation site and the model used for investigation. For example, silk scaffolds, films and hydrogels are commonly implanted subcutaneously (Thurber, Omenetto et al. 2015) and are expected to result in different biological responses when compared to that triggered by their placement into immune privileged sites such as the back of the eye (e.g. vitreous, retina), the testicles and, to some extent, the articular cartilage. A different biological response would be expected yet again following the administration of silk directly into tissues of the immune system, such as the spleen, lymph nodes or liver.

Information is currently limited regarding the tissue response towards silk hydrogels, but the available data are encouraging (Etienne, Schneider et al. 2009, Critchfield, McCabe et al. 2014, Hamilton, Shih et al. 2015). For example, injection of sonication-induced silk hydrogels into the cervix of pregnant rats (gestational day 13) as a potential therapeutic approach to preterm birth (Critchfield, McCabe et al. 2014, Brown, Partlow et al. 2016) resulted in a mild foreign body response similar to that observed with polyglycolic acid and poly(ethylene terephthalate) sutures (Critchfield, McCabe et al. 2014). These in vivo studies assessed the biological response at 4 days post treatment, and they were supplemented by in vitro studies with human cervical cells, which showed no up-regulation of inflammatory markers. However, the longer-term effects, such as longitudinal inflammatory responses, biodegradation or impacts on pregnancy (e.g. a shift to a post-term pregnancy), are currently unknown (Critchfield, McCabe et al. 2014). 
Hydrogels: Design, Synthesis \& Application in Drug Delivery \& Regenerative Medicine. Edited by Thakur Raghu Raj Singh, Garry Laverty and Ryan Donnelly

2017 SCIENCE PUBLISHERS

(An Imprint of CRC Press/ Taylor \& Francis Group)

One longer-term study compared silk hydrogels to collagen type I hydrogels both in vitro and in vivo (Etienne, Schneider et al. 2009). Nude mice, at one and two weeks post implantation of silk hydrogels, showed signs of inflammation in the tissues surrounding the silk hydrogels, as indicated by the presence of eosinophils, neutrophils and macrophages around the hydrogel periphery, but showed no infiltration of these cells within the hydrogel network. However, this silk-induced inflammatory response was less intense than that observed for collagen hydrogels, which attracted numerous neutrophils, eosinophils and macrophages that infiltrated the material and subsequently degraded the hydrogel completely within 4 weeks. At week 4, the inflammation around the silk hydrogel was greatly reduced and the hydrogel had cracks that were populated by spindle shaped cells; at 3 months, no inflammatory cells could be detected in or around the silk hydrogels, but vascularisation was apparent and the interstitial spaces were populated by stromal cells. Corroborating these observations are results from subcutaneously implanted $8 \% \mathrm{w} / \mathrm{v}$ silk hydrogels in rats, where significant hydrogel remodelling was initiated at 15 weeks post implantation, resulting in vascularisation, loss of hydrogel shape and degradation (Hamilton, Shih et al. 2015).

\section{Silk Biodegradation}

Most studies reporting the in vivo biodegradation of silk have assessed films and scaffolds; only a few studies have characterized silk hydrogels. One study used sonication-induced sol-gels that were preformed ex vivo and subsequently surgically implanted in mice. Cylindrically shaped $8 \times$ $6 \mathrm{~mm}$ silk hydrogels generated from a $4 \% \mathrm{w} / \mathrm{v}$ silk solution were subcutaneously implanted in nude mice and the biological response assessed over 12 weeks (Etienne, Schneider et al. 2009). At the endpoint of this study, fragmentation of the silk hydrogel was reported, although the 
Hydrogels: Design, Synthesis \& Application in Drug Delivery \& Regenerative Medicine. Edited by Thakur Raghu Raj Singh, Garry Laverty and Ryan Donnelly

2017 SCIENCE PUBLISHERS

(An Imprint of CRC Press/ Taylor \& Francis Group)

hydrogel maintained its shape and showed signs of vascularisation (Etienne, Schneider et al. 2009). However, the exact extent of silk hydrogel degradation was not assessed as well as the process of vascularisation.

Silk is biodegradable due to its susceptibility to proteases and enzyme-catalysed hydrolysis reactions. In particular, the disulphide bond between the light and heavy chains, as well as the amorphous silk sequences, are highly susceptible to degradation. In contrast, the crystalline regions are most resistant to proteolytic degradation due to reduced chain flexibility and access. Therefore, the $\beta$-sheet content has a protective effect on silk degradation both in vitro (Li, Ogiso et al. 2003, Horan, Antle et al. 2005, Meinel, Hofmann et al. 2005, Numata, Cebe et al. 2010, Brown, Lu et al. 2015) and in vivo (Meinel, Hofmann et al. 2005, Wang, Rudym et al. 2008). However, differences in packing geometries exist within the crystalline regions, ranging from tight to looser chain packing. This, in turn, results in differences in degradation behaviour; the tightly packed crystalline regions are made up of highly ordered $\beta$-sheets while the looser packing contains less ordered $\beta$-sheets as well as turn-and random-coil structures (Numata, Cebe et al. 2010). In particular, the more loosely packed crystalline regions are susceptible to degradation and are degraded first.

Protease XIV is a useful proteolytic model enzyme for uncovering some of the fundamentals of silk degradation over short study intervals (e.g. hours to days). For example, protease XIV studies showed that digestion of the more loosely packed $\beta$-sheets yielded nanofibrils around $4 \mathrm{~nm}$ thick and $80-100 \mathrm{~nm}$ wide that persisted over the course of the in vitro degradation study (24 h), as well as soluble silk fragments. Cytotoxicity studies indicated that 
Hydrogels: Design, Synthesis \& Application in Drug Delivery \& Regenerative Medicine. Edited by Thakur Raghu Raj Singh, Garry Laverty and Ryan Donnelly

2017 SCIENCE PUBLISHERS

(An Imprint of CRC Press/ Taylor \& Francis Group)

these protease XIV digested silk samples reduced cell viability $\left(\mathrm{IC}_{50} 75 \mu \mathrm{g} / \mathrm{ml}\right)$, whereas diseaseassociated $\beta$-sheets of amyloid $\beta$-peptide fibrils $\left(\mathrm{IC}_{50} 20 \mu \mathrm{g} / \mathrm{ml}\right)$ were more cytotoxic (Numata, Cebe et al. 2010).

At first sight, these observations might seem alarming, but a number of points need to be considered. First, no similar observations were made with silk that was degraded using $\alpha$ chymotrypsin to yield insoluble silk crystals and soluble hydrophilic domains; these showed no cytotoxicity at the maximum tested concentration $\left(\mathrm{IC}_{50}>225 \mu \mathrm{g} / \mathrm{ml}\right)$, in sharp contrast to protease XIV degradation that generated soluble fragments with $\beta$-sheet structures (Numata, Cebe et al. 2010). Second, protease XIV is a non-mammalian enzyme; therefore, its degradation products are not necessarily encountered in vivo. Third, the degradation products generated by chymotrypsin, a mammalian enzyme, showed no cytotoxicity. Fourth, in vivo studies, and indeed observations in human clinical trials and during routine use of silk sutures, have not shown any overt adverse effects due to inadequate biodegradation. The US Pharmacopeia classifies silk sutures as non-resorbable. However, this is based on the definition that the material "loses most of its tensile strength within 60 days" post-implantation in vivo. Silk sutures significantly degrade within 1 year, and they are completely resorbed within 2 years (Altman, Diaz et al. 2003).

In vitro studies and mapping of the silk primary sequence to a known protease cleavage site indicated that serine proteases (e.g. $\alpha$-chymotrypsin, collagenase) and matrix metalloproteinases (MMPs) (MMP-1, interstitial collagenase, and MMP-2, gelatinase A) are particularly active in silk degradation (Brown, Lu et al. 2015). Our current understanding of silk degradation (Brown, Lu et al. 2015) and emerging evidence suggest that the amorphous regions of silk hydrogels are 
Hydrogels: Design, Synthesis \& Application in Drug Delivery \& Regenerative Medicine. Edited by Thakur Raghu Raj Singh, Garry Laverty and Ryan Donnelly

2017 SCIENCE PUBLISHERS

(An Imprint of CRC Press/ Taylor \& Francis Group)

degraded first. Thus, at an equivalent silk and $\beta$-sheet content, silk in hydrogel form is likely to be degraded fastest due to the open hydrogel frame structure, followed by porous scaffolds and films, where the monolithic structure restricts water ingress and thus hinders access of enzymes to the amorphous silk segments.

\section{Silk Hydrogel Manufacture}

Silk hydrogels can be broadly classified into physically (Ayub, Arai et al. 1993) and chemically crosslinked systems (Min, Nakamura et al.).

\section{Physically Crosslinked Silk Hydrogels}

A number of strategies have been explored to generate physically crosslinked silk hydrogels, including (i) ultrasound (Wang, Kluge et al. 2008), (ii) vortexing (Yucel, Cebe et al. 2009), (iii) $\mathrm{CO}_{2}$ acidification (Floren, Spilimbergo et al. 2012), (iv) non-solvent induced phase separation (Kasoju, Hawkins et al. 2016), (v) electrical fields (Leisk, Lo et al. 2010, Lu, Huang et al. 2011), (vi) temperature (Kim, Park et al. 2004), vii) osmotic stress (Kim, Park et al. 2004, Ribeiro, de Moraes et al. 2014) and (viii) $\mathrm{pH}$ (Ayoub, Garb et al. 2007). The underlying basis of all these systems is the self-assembling behaviour of silk, which forms hydrogels due to the physical entanglements and hydrogen bonding between hydrophobic domains of the silk block copolymer. Under aqueous conditions, this self-assembly into micelles is a thermodynamic process, whose kinetics depend on molecular mobility, charge, hydrophilic interactions and concentration (Lu, Zhu et al. 2012). Therefore, any changes in these parameters due to the chosen processing technique will directly affect the final format of the silk. 
Hydrogels: Design, Synthesis \& Application in Drug Delivery \& Regenerative Medicine. Edited by Thakur Raghu Raj Singh, Garry Laverty and Ryan Donnelly

2017 SCIENCE PUBLISHERS

(An Imprint of CRC Press/ Taylor \& Francis Group)

Emerging evidence suggests that the silk I format is promoted by a high silk solution concentration $(20 \% \mathrm{w} / \mathrm{v})$ that causes the silk micelles to assemble initially into nanofilamentous structures. These silk I structures are metastable and do not involve changes in secondary structure, but they undergo weak hydrogen bonding as well as hydrophobic and electrostatic interactions (Matsumoto, Chen et al. 2006, Lu, Zhu et al. 2012). This initial stage is followed by changes to the secondary structure, including the formation of $\beta$-sheets (Matsumoto, Chen et al. 2006), which give rise to strong intermolecular interactions and stabilise the silk hydrogel network, making the hydrogel structure essentially irreversible (Matsumoto, Chen et al. 2006). In contrast, low silk concentrations $(1 \% \mathrm{w} / \mathrm{v})$ promote the formation of silk micelles that transition directly into micellar aggregates ( $\mathrm{Lu}, \mathrm{Zhu}$ et al. 2012).

Shearing of silk aqueous solutions (i.e. by vortexing, sonication, etc.) speeds up the selfassembling kinetics and results in the formation of silk hydrogels within minutes to hours. These hydrogels transition from a random coil conformation to a $\beta$-sheet that contains some inter-chain physical crosslinks. In time, large numbers of inter-chain $\beta$-sheet crosslinks form and stabilise the overall structure (Wang, Kluge et al. 2008). The kinetics of this process can be further expedited by increasing the silk concentration, solution temperature, concentration of $\mathrm{K}^{+}$ions, acidity (i.e. low $\mathrm{pH}$ ) and energy input. However, excessive sonication leads to fragmentation of the silk fibres and negatively impacts hydrogel formation (Samal, Kaplan et al. 2013).

The hydrogels that are produced by reducing the solution $\mathrm{pH}$ to a value close to the silk isoelectric point ( $\mathrm{pH}$ 4.2) are characterized by extensive $\beta$-sheets (Ayub, Arai et al. 1993). The responsiveness of silk to $\mathrm{pH}$ is governed by its amphiphilic nature, due to the presence of large 
Hydrogels: Design, Synthesis \& Application in Drug Delivery \& Regenerative Medicine. Edited by Thakur Raghu Raj Singh, Garry Laverty and Ryan Donnelly

2017 SCIENCE PUBLISHERS

(An Imprint of CRC Press/ Taylor \& Francis Group)

hydrophobic blocks interspersed with hydrophilic amorphous regions, and due to its hydrophilic

C- and N-termini. The N-terminus of the silk heavy chain is acidic (isoelectric point 4.6) and the C-terminus is basic (isoelectric point 10.5) whereas the C-terminus of the light chain is acidic (isoelectric point 5.1) (Kapoor and Kundu 2016). The acidic groups become protonated at low $\mathrm{pH}$, leading to a reduced charge-charge repulsion that subsequently allows silk to adopt a more ordered state, with the formation of $\beta$-sheets that exclude water (He, Zhang et al. 2012).

The use of high pressure $\mathrm{CO}_{2}$ during silk hydrogel manufacture acidifies the silk solution while changing the hydration shell and increasing the propensity for reduced volume states of silk. At high pressure, $\mathrm{CO}_{2}$ generates carbonic acid and, according to Henry's law, this process is directly proportional to the applied pressure. Experimental and theoretical calculations have shown the occurrence of robust gelation within 2 hours, yielding silk hydrogels that were at least 2 fold more robust mechanically than hydrogels generated using traditional $\mathrm{pH}$ approaches (Floren, Spilimbergo et al. 2012).

Water exclusion and subsequent $\beta$-sheet formation have been proposed for silk hydrogels formed under osmotic stress, $\mathrm{pH}$, increased temperature (Matsumoto, Chen et al. 2006) and nonsolvent induced phase separation (Kasoju, Hawkins et al. 2016). However, silk hydrogels generated using low electrical DC fields differ markedly from those formed by these other processes, as they are formed through electrogelation (and are therefore referred to as e-gels). They deposit on the positive electrode and their formation is completed within minutes (Leisk, Lo et al. 2010). 
Hydrogels: Design, Synthesis \& Application in Drug Delivery \& Regenerative Medicine. Edited by Thakur Raghu Raj Singh, Garry Laverty and Ryan Donnelly 2017 SCIENCE PUBLISHERS (An Imprint of CRC Press/ Taylor \& Francis Group)

A
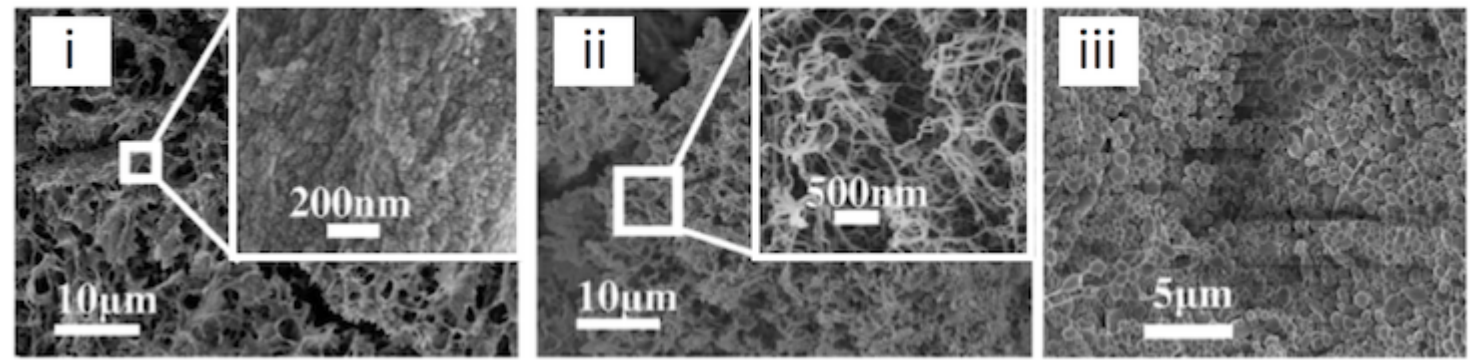

Figure 3 Silk e-gel processing, characterisation and structure. Scanning electron micrographs of different hydrogel morphologies derived from silk solution (i) of low and (ii) high concentration and (iii) silk e-gel. Reproduced with permission from (Lu, Zhu et al. 2012))

The electrogelation process is based on local $\mathrm{pH}$ changes that occur due to water electrolysis. The local $\mathrm{pH}$ drops at the positive electrode to a value below the isoelectric point of silk, thereby enabling silk deposition on the electrode (Lu, Huang et al. 2011, Kojic, Panzer et al. 2012). The formation of the silk hydrogel can be predicted by ion electrodiffusion (Kojic, Panzer et al. 2012).

Analysis of the secondary structure of the silk in e-gels indicated a transition from a random coil conformation to a helical conformation, but no changes in $\beta$-sheet content (as typically seen for sonicated or vortexed silk hydrogels). Reversal of the electric field led to a dissociation of the silk hydrogel and subsequent formation at the new positive electrode; this process could undergo many repeat cycles (Leisk, Lo et al. 2010). High resolution imaging showed that these hydrogels were formed from nanometre sized silk micelles that were 
Hydrogels: Design, Synthesis \& Application in Drug Delivery \& Regenerative Medicine. Edited by Thakur Raghu Raj Singh, Garry Laverty and Ryan Donnelly

2017 SCIENCE PUBLISHERS

(An Imprint of CRC Press/ Taylor \& Francis Group)

metastable (Lu, Huang et al. 2011). In the presence of a weak electric field, these silk micelles formed larger spherical structures that ranged from nanometres to several micrometres in size. These particles were able to assemble into hydrogels because the negative surface charge of the silk particles was screened by the low $\mathrm{pH}$ in the vicinity of the positive electrode (Lu, Huang et al. 2011). Overall, silk e-gels have been proposed for a range of biomedical applications due to their ability to control silk hydrogel assembly and to trigger the release of silk particles upon charge reversal, and because of the excellent adhesive properties of these hydrogels (Leisk, Lo et al. 2010, Lu, Huang et al. 2011, Kojic, Panzer et al. 2012).

Physically crosslinked silk hydrogels are particularly promising for drug delivery and biomedical applications because their formation does not rely on chemical crosslinking and therefore avoids the use of potentially harmful agents such as organic solvents, chemical initiators or UV irradiation. Residual chemicals can leach from chemically crosslinked hydrogels, while UV-based polymerisation techniques are incompatible with cell viability. Silk hydrogels formed by sonication and vortexing are particularly well suited for drug and cell delivery because the payload can be added after the silk treatment but prior to the onset of gelation (Seib and Kaplan 2013). However, physically crosslinked silk hydrogels show limited elastic behaviour and plastic deformation occurs typically at strains greater than $10 \%$.

Most physically crosslinked silk hydrogels rely on $\beta$-sheet crystals to stabilise the hydrogel network, which results in brittleness that prevents long range displacements and culminates in low elastic behaviour. The e-gels are notable exceptions, as they have outstanding elastic properties and can withstand strains of up to $2,500 \%$. Nevertheless, they require the use of an 
Hydrogels: Design, Synthesis \& Application in Drug Delivery \& Regenerative Medicine. Edited by Thakur Raghu Raj Singh, Garry Laverty and Ryan Donnelly

2017 SCIENCE PUBLISHERS

(An Imprint of CRC Press/ Taylor \& Francis Group)

electric current to generate the low $\mathrm{pH}$; an approach that is not compatible with cells. Therefore, alternative silk hydrogels are being developed that show better elastic behaviour.

\section{Chemically Crosslinked Silk Hydrogels}

Chemically crosslinked silk hydrogels have been synthesised using a range of chemistries (Kapoor and Kundu 2016). For example, horseradish peroxidase has been used to crosslink the phenol groups in the tyrosine amino acids in the silk protein (Partlow, Hanna et al. 2014). This generated elastic silk hydrogels that could withstand a shear strain of $100 \%$ and a compressive strain greater than $70 \%$. The stiffness of these silk hydrogels could be fine tuned to range from 200 to $10,000 \mathrm{~Pa}$ by adjusting the silk degumming times between 60 and 10 minutes, respectively. These crosslinked silk hydrogels are optically clear over the visible wavelength spectrum (Partlow, Hanna et al. 2014), making them different from physically crosslinked gels that typically contain nanocrystalline regions that scatter light. Horseradish peroxidase crosslinked silk hydrogels have subsequently been exposed to low-energy ultrafast laser pulses to generate complex 3D patterns within the hydrogels that could subsequently be populated with cells (Applegate, Coburn et al. 2015). Riboflavin, a photoactive crosslinker, has recently been used to generate in situ crosslinked silk corneal prostheses with the aim of improving visual acuity (Applegate, Partlow et al. 2016).

\section{Examples of Silk Hydrogels for Cell and Drug Delivery}

Silk hydrogels have been studied for a broad range of biomedical applications, including cell and drug delivery. For example, self-assembling silk hydrogels were developed for breast cancer focal therapy (Seib, Pritchard et al. 2013). Sonication-induced hydrogels were drug loaded prior to the 
Hydrogels: Design, Synthesis \& Application in Drug Delivery \& Regenerative Medicine. Edited by Thakur Raghu Raj Singh, Garry Laverty and Ryan Donnelly 2017 SCIENCE PUBLISHERS (An Imprint of CRC Press/ Taylor \& Francis Group)

onset of gelation and drug release was subsequently assessed in vitro. Drug release was not affected by the silk degumming time, but doxorubicin release from these hydrogels was significantly affected by the weight percentage of the silk. Hydrogels with the lowest silk content released the drug fastest ( $27 \%$ cumulative drug release over 30 days), whereas the hydrogels with the highest amount of silk had the slowest drug release (17\% cumulative drug release over 30 days) (Seib, Pritchard et al. 2013). Injection of drug loaded silk hydrogels in close proximity to well-established orthotopic breast tumours, followed by in vivo monitoring and necropsy, showed that these hydrogels were well tolerated in biological systems. Complete tumour regression was observed in two of five animals investigated, and breast cancer metastasis was reduced when compared to animals administered an equivalent amount of doxorubicin by bolus intravenous injection (Seib, Pritchard et al. 2013). 
Hydrogels: Design, Synthesis \& Application in Drug Delivery \& Regenerative Medicine. Edited by Thakur Raghu Raj Singh, Garry Laverty and Ryan Donnelly 2017 SCIENCE PUBLISHERS

(An Imprint of CRC Press/ Taylor \& Francis Group)

A

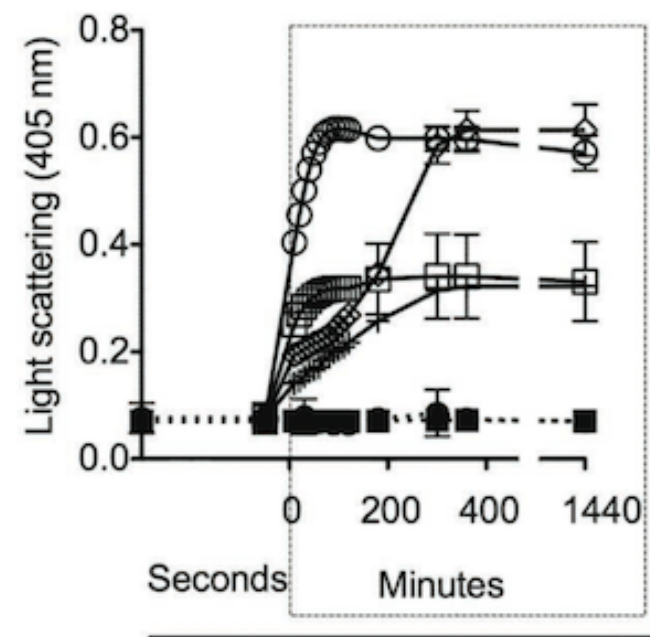

Time

C

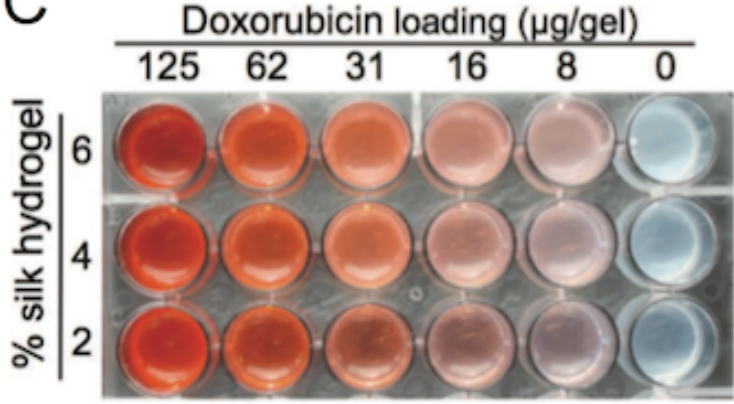

E $\quad \nabla$ Control

0 Doxorubicin i.v.

$\square$ Silk hydrogel + doxorubicin
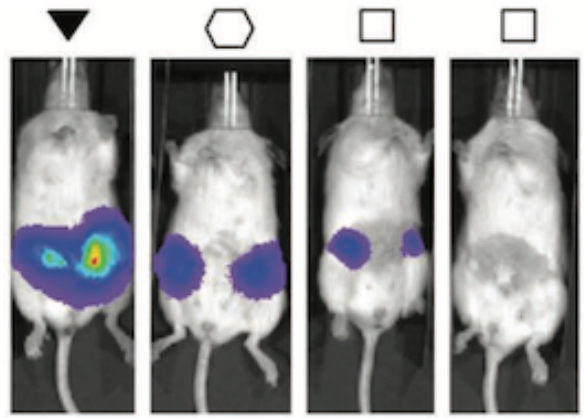

0.8

\begin{abstract}
$\begin{array}{lll}0.6 & 0.4 & 0.2\end{array}$
\end{abstract}
Flux $\left(\mathrm{p} / \mathrm{sec} / \mathrm{cm}^{2} / \mathrm{sr}\right) \times 10^{9}$
B

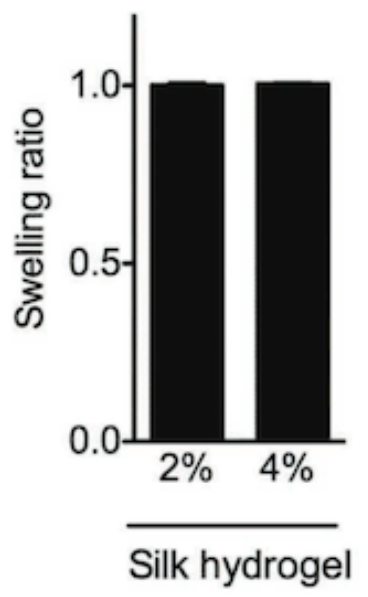

Silk Sonification (wt\%) (sec)

는 2 -

$+230$

$\diamond 430$

$\begin{array}{lll}\square & 2 & 45 \\ 0 & 4 & 45\end{array}$

D
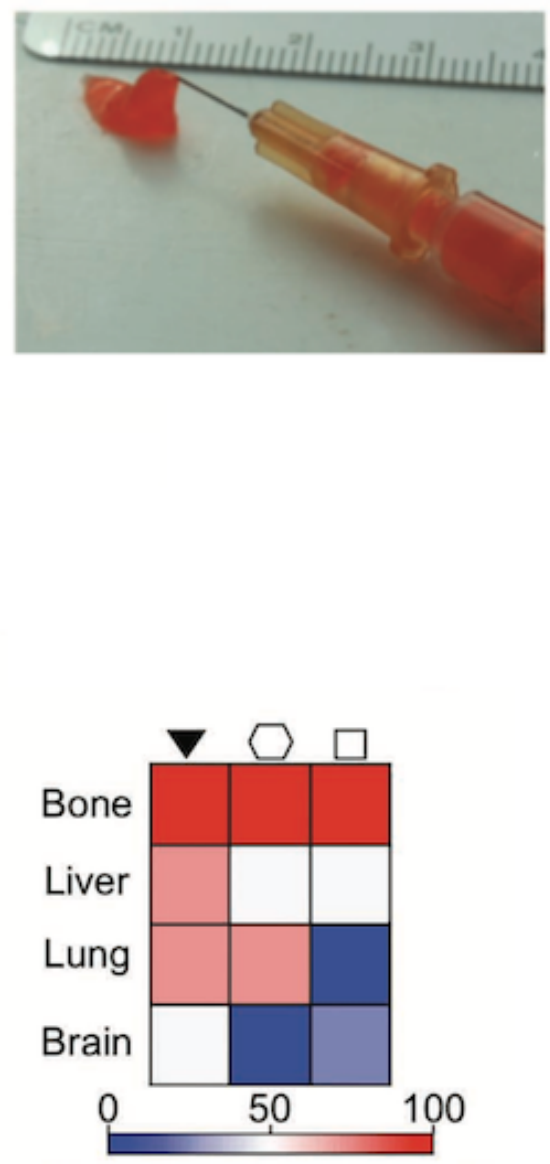

Metastasis frequency (\%) 
Hydrogels: Design, Synthesis \& Application in Drug Delivery \& Regenerative Medicine. Edited by Thakur Raghu Raj Singh, Garry Laverty and Ryan Donnelly

2017 SCIENCE PUBLISHERS

(An Imprint of CRC Press/ Taylor \& Francis Group)

Figure 4 Self-assembling silk hydrogels for focal breast cancer focal therapy. (A) Impact of processing parameters on the sol-gel kinetics of silk. (B) Silk hydrogels show no swelling post sol-gel transition. (C) Silk hydrogels can be readily loaded with drug; here, doxorubicin was added prior to the onset of gelation. (D) Injectability of drug loaded silk hydrogels. (E) Response of human breast cancer xenografts to treatment. Bioluminescence imaging of primary breast tumours at the end of the study and extent of metastasis. (Reproduced with permission from (Seib, Pritchard et al. 2013))

Sonication-induced silk hydrogels have also been used for ocular drug delivery of an antivascular endothelial growth factor (bevacizumab) (Lovett, Wang et al. 2015). In vitro drug release from $2 \% \mathrm{w} / \mathrm{v}$ silk hydrogels loaded with $5.0 \mathrm{mg}$ of bevacizumab revealed a controlled drug release over 90 days for both doses. By contrast, the control drug formulation, Avastin, was eliminated form the test system within 30 days. The hydrogels showed an initial burst release (up to day 10) and a similar release profile to Avastin between days 11 and 20, but then showed a sustained zero order drug release over the remaining 60 days of the study. By contrast, drug release was exhausted for the Avastin control group by day 30. Pharmacokinetic assessment of the bevacizumab loaded silk hydrogels revealed an increase of two to three fold in the terminal elimination half-life in the vitreous and aqueous humour. In vivo biocompatibility studies indicated no overt adverse reactions due to the silk hydrogels over the course of the study, as verified by gross examination of the hydrogels, ophthalmic examination and fundus imaging. The silk hydrogels showed some signs of degradation from day 30 onwards, although the hydrogels (50 $\mu$ l volume) were still present at the end of the study (day 90) (Lovett, Wang et al. 2015). 
Hydrogels: Design, Synthesis \& Application in Drug Delivery \& Regenerative Medicine. Edited by Thakur Raghu Raj Singh, Garry Laverty and Ryan Donnelly

2017 SCIENCE PUBLISHERS

(An Imprint of CRC Press/ Taylor \& Francis Group)

Physically crosslinked silk hydrogels show shear thinning, making them well suited for injection. Silk also has a remarkable ability to stabilise therapeutic proteins, largely due to the nanocrystalline regions that perform several functions, including providing a buffering capacity, tailoring water content at the nanoscale level and providing physical protection (reviewed in (Pritchard, Dennis et al. 2012)). Therefore, silk hydrogels serve as a delivery vehicle but they also provide active support for the payload.

The excellent material properties of silk have supported the development of various hydrogel systems for soft and hard tissue engineering applications (Omenetto and Kaplan 2010). More recently, silk hydrogels have been assessed as a potential delivery system for pancreatic islet transplantation (Hamilton, Shih et al. 2015). Vortex induced silk hydrogels were generated and pancreatic islets were added prior to the onset of gelation and compared in vivo to pancreatic islet transplantations in the absence of silk. A third treatment group included silk hydrogel transplants that contained pancreatic islets and mesenchymal stem cells (MSCs). Diabetic mice regained glycaemic control, with the best control observed with the pancreatic islets and MSC silk hydrogels. However, histological assessment indicated that the MSCs had not only supported the graft but had also differentiated into bone and cartilage; an outcome that was not intended. Therefore, silk hydrogels not only served as a delivery vehicle but also mimicked the extracellular matrix (ECM) that stem cells sense and respond to (Hamilton, Shih et al. 2015). The viscoelastic properties of physically crosslinked silk hydrogels have received little attention to date, although emerging evidence indicates that rapid stress relaxation of viscoelastic hydrogels supports osteogenesis of MSCs (Chaudhuri, Gu et al. 2015). Indeed, ECMs found in vivo are viscoelastic; therefore, physically crosslinked silk hydrogels are well placed to serve as ECM 
Hydrogels: Design, Synthesis \& Application in Drug Delivery \& Regenerative Medicine. Edited by Thakur Raghu Raj Singh, Garry Laverty and Ryan Donnelly

2017 SCIENCE PUBLISHERS

(An Imprint of CRC Press/ Taylor \& Francis Group)

mimetics. However, these silk hydrogels are brittle, so alternatives to chemical crosslinking need to be explored. In this context, the inclusion of silk fibres has emerged as a valuable strategy (Yodmuang, McNamara et al. 2015), and silk fibre reinforced silk hydrogels have now been successfully used for the culture of chondrocytes. At day 40, these tissue engineered cartilage constructs closely resembled native tissue in both composition and physical performance (Yodmuang, McNamara et al. 2015).

The spectrum of use of silk hydrogels goes beyond typical cell and drug delivery applications. For example, as part of the $3 \mathrm{R}$ initiative (i.e. replacement, refinement and reduction of animal experiments), silk-based brain dummies made from silk scaffolds and collagen type I hydrogels have been developed to study traumatic brain injury (Tang-Schomer, White et al. 2014). These constructs faithfully recapitulate the brain's biophysical properties (Tang-Schomer, White et al. 2014) and, in future studies, could be used as a model system to study neurophysiology. Print technologies have been used to process both chemically modified $B$. mori silk solution (Suntivich, Drachuk et al. 2014) and recombinant spider silks (Schacht, Jungst et al. 2015). The spider silks were used as aqueous solutions to encapsulate cells and were then allowed to undergo gelation. This mixture was subsequently extruded by application of pressure through an electromagnetically controlled valve. The resulting 3D constructs could be readily manufactured to a $500 \mu \mathrm{m}$ resolution, and they supported cell viability.

\section{Summary and Outlook}

This chapter summarises recent developments in the production and use of silk-based hydrogels for cell and drug delivery. We have primarily focused on silk hydrogels, but have used other silk 
Hydrogels: Design, Synthesis \& Application in Drug Delivery \& Regenerative Medicine. Edited by Thakur Raghu Raj Singh, Garry Laverty and Ryan Donnelly 2017 SCIENCE PUBLISHERS (An Imprint of CRC Press/ Taylor \& Francis Group)

formats for reference purposes, as a substantial body of work is available regarding silk particles, films and scaffolds for drug and cell delivery (Kasoju and Bora 2012, Seib and Kaplan 2013, Yucel, Lovett et al. 2014, Zhao, Li et al. 2015). This chapter has also omitted the development of silk "alloys" (e.g. recombinantly engineered silk elastins, reviewed in (Rnjak-Kovacina and Kaplan 2013, Price, Poursaid et al. 2014)) due to space constraints. Overall, silk is a truly remarkable biopolymer that will continue to amaze us. Clearly, at the time of this writing, silk is poised to change the way we deliver cells and drugs in the clinical setting.

\section{Acknowledgement}

The author would like to thank Thidarat Wongpinyochit for feedback on the manuscript and Dr. Jelena Rnjak-Kovacina, University of New South Wales, Sydney, Australia for insightful discussion and advice. This research was supported in part by a Marie Curie FP7 Career Integration Grant 334134 within the $7^{\text {th }}$ European Union Framework Program and an EPSRC First Grant EP/N03127X/1.

\section{References}

Altman, G. H., Diaz, F., Jakuba, C., Calabro, T., Horan, R. L., Chen, J., Lu, H., Richmond, J. and Kaplan, D. L. 2003. Silk-based biomaterials. Biomaterials 24: 401-416.

Applegate, M. B., Coburn, J., Partlow, B. P., Moreau, J. E., Mondia, J. P., Marelli, B., Kaplan, D. L. and Omenetto, F. G. 2015. Laser-based three-dimensional multiscale micropatterning of biocompatible hydrogels for customized tissue engineering scaffolds. Proc. Natl. Acad. Sci. U S A 112: 12052-12057. 
Hydrogels: Design, Synthesis \& Application in Drug Delivery \& Regenerative Medicine. Edited by Thakur Raghu Raj Singh, Garry Laverty and Ryan Donnelly 2017 SCIENCE PUBLISHERS (An Imprint of CRC Press/ Taylor \& Francis Group)

Applegate, M. B., Partlow, B. P., Coburn, J., Marelli, B., Pirie, C., Pineda, R., Kaplan, D. L. and Omenetto, F. G. 2016. Photocrosslinking of Silk Fibroin Using Riboflavin for Ocular Prostheses. Adv. Mater.

Asakura, T., Suzuki, Y., Nakazawa, Y., Holland, G. P. and Yarger, J. L. 2013. Elucidating silk structure using solid-state NMR. Soft Matter 9: 11440-11450.

Askarieh, G., Hedhammar, M., Nordling, K., Saenz, A., Casals, C., Rising, A., Johansson, J. and Knight, S. D. 2010. Self-assembly of spider silk proteins is controlled by a pH-sensitive relay. Nature 465: 236-238.

Ayoub, N. A., Garb, J. E., Tinghitella, R. M., Collin, M. A. and Hayashi, C. Y. 2007. Blueprint for a high-performance biomaterial: full-length spider dragline silk genes. PLoS One 2: e514.

Ayub, Z. H., Arai, M. and Hirabayashi, K. 1993. Mechanism of the gelation of fibroin solution. Biosci. Biotech. Biochem. 57: 1910-1912.

Brown, J., Lu, C. L., Coburn, J. and Kaplan, D. L. 2015. Impact of silk biomaterial structure on proteolysis. Acta Biomater. 11: 212-221.

Brown, J. E., Partlow, B. P., Berman, A. M., House, M. D. and Kaplan, D. L. 2016. Injectable silk-based biomaterials for cervical tissue augmentation: an in vitro study. Am. J. Obstet. Gynecol. 214: 118 e111-119.

Buehler, M. J. 2013. Materials by Design-A Perspective From Atoms to Structures. MRS Bull. 38: $169-176$. 
Hydrogels: Design, Synthesis \& Application in Drug Delivery \& Regenerative Medicine. Edited by Thakur Raghu Raj Singh, Garry Laverty and Ryan Donnelly

2017 SCIENCE PUBLISHERS

(An Imprint of CRC Press/ Taylor \& Francis Group)

Chaudhuri, O., Gu, L., Klumpers, D., Darnell, M., Bencherif, S. A., Weaver, J. C., Huebsch, N.,

Lee, H. P., Lippens, E., Duda, G. N. and Mooney, D. J. 2015. Hydrogels with tunable stress

relaxation regulate stem cell fate and activity. Nat. Mater.

Chung, H., Kim, T. Y. and Lee, S. Y. 2012. Recent advances in production of recombinant spider silk proteins. Curr. Opin. Biotechnol. 23: 957-964.

Critchfield, A. S., McCabe, R., Klebanov, N., Richey, L., Socrate, S., Norwitz, E. R., Kaplan, D.

L. and House, M. 2014. Biocompatibility of a sonicated silk gel for cervical injection during pregnancy: in vivo and in vitro study. Reprod. Sci. 21: 1266-1273.

De Vita, R., Buccheri, E. M., Pozzi, M. and Zoccali, G. 2014. Direct to implant breast reconstruction by using SERI, preliminary report. J. Exp. Clin. Cancer Res. 33: 78.

Ebrahimi, D., Tokareva, O., Rim, N. G., Wong, J. Y., Kaplan, D. L. and Buehler, M. J. 2015. Silk - its mysteries, how it is made, and how it is used. ACS Biomater. Sci. Eng. 1: 864-876.

Etienne, O., Schneider, A., Kluge, J. A., Bellemin-Laponnaz, C., Polidori, C., Leisk, G. G., Kaplan, D. L., Garlick, J. A. and Egles, C. 2009. Soft tissue augmentation using silk gels: an in vitro and in vivo study. J. Periodontol. 80: 1852-1858.

Exler, J. H., Hummerich, D. and Scheibel, T. 2007. The amphiphilic properties of spider silks are important for spinning. Angew. Chem. Int. Ed. Engl. 46: 3559-3562.

Fine, N. A., Lehfeldt, M., Gross, J. E., Downey, S., Kind, G. M., Duda, G., Kulber, D., Horan, R., Ippolito, J. and Jewell, M. 2015. SERI surgical scaffold, prospective clinical trial of a silk-derived 
Hydrogels: Design, Synthesis \& Application in Drug Delivery \& Regenerative Medicine. Edited by Thakur Raghu Raj Singh, Garry Laverty and Ryan Donnelly 2017 SCIENCE PUBLISHERS (An Imprint of CRC Press/ Taylor \& Francis Group)

biological scaffold in two-stage breast reconstruction: 1-year data. Plast. Reconstr. Surg. 135: 339-351.

Floren, M. L., Spilimbergo, S., Motta, A. and Migliaresi, C. 2012. Carbon dioxide induced silk protein gelation for biomedical applications. Biomacromolecules 13: 2060-2072.

Gatesy, J., Hayashi, C., Motriuk, D., Woods, J. and Lewis, R. 2001. Extreme diversity, conservation, and convergence of spider silk fibroin sequences. Science 291: 2603-2605.

Ha, S. W., Gracz, H. S., Tonelli, A. E. and Hudson, S. M. 2005. Structural study of irregular amino acid sequences in the heavy chain of Bombyx mori silk fibroin. Biomacromolecules 6: 2563-2569.

Hagn, F., Eisoldt, L., Hardy, J. G., Vendrely, C., Coles, M., Scheibel, T. and Kessler, H. 2010. A conserved spider silk domain acts as a molecular switch that controls fibre assembly. Nature 465: 239-242.

Hamilton, D. C., Shih, H. H., Schubert, R. A., Michie, S. A., Staats, P. N., Kaplan, D. L. and Fontaine, M. J. 2015. A silk-based encapsulation platform for pancreatic islet transplantation improves islet function in vivo. J. Tissue Eng. Regen. Med.

Hardy, J. G. and Scheibel, T. R. 2009. Silk-inspired polymers and proteins. Biochem. Soc. Trans. 37: $677-681$.

He, Y. X., Zhang, N. N., Li, W. F., Jia, N., Chen, B. Y., Zhou, K., Zhang, J., Chen, Y. and Zhou, C. Z. 2012. N-Terminal domain of Bombyx mori fibroin mediates the assembly of silk in response to pH decrease. J. Mol. Biol. 418: 197-207. 
Hydrogels: Design, Synthesis \& Application in Drug Delivery \& Regenerative Medicine. Edited by Thakur Raghu Raj Singh, Garry Laverty and Ryan Donnelly 2017 SCIENCE PUBLISHERS (An Imprint of CRC Press/ Taylor \& Francis Group)

Horan, R. L., Antle, K., Collette, A. L., Wang, Y., Huang, J., Moreau, J. E., Volloch, V., Kaplan, D. L. and Altman, G. H. 2005. In vitro degradation of silk fibroin. Biomaterials 26: 3385-3393.

Inoue, S., Tanaka, K., Arisaka, F., Kimura, S., Ohtomo, K. and Mizuno, S. 2000. Silk fibroin of Bombyx mori is secreted, assembling a high molecular mass elementary unit consisting of $\mathrm{H}-$ chain, L-chain, and P25, with a 6:6:1 molar ratio. J. Biol. Chem. 275: 40517-40528.

Inoue, S., Tanaka, K., Tanaka, H., Ohtomo, K., Kanda, T., Imamura, M., Quan, G.-X., Kojima, K., Yamashita, T., Nakajima, T., Taira, H., Tamura, T. and Mizuno, S. 2004. Assembly of the silk fibroin elementary unit in endoplasmic reticulum and a role of L-chain for protection of $\alpha 1,2-$ mannose residues in N-linked oligosaccharide chains of fibrohexamerin/P25. Eur. J. Biochem. 27: $356-366$.

Jin, H. J. and Kaplan, D. L. 2003. Mechanism of silk processing in insects and spiders. Nature 424: 1057-1061.

Kapoor, S. and Kundu, S. C. 2016. Silk protein-based hydrogels: Promising advanced materials for biomedical applications. Acta Biomater. 31: 17-32.

Kasoju, N. and Bora, U. 2012. Silk fibroin in tissue engineering. Adv. Healthc. Mater. 1: 393412.

Kasoju, N., Hawkins, N., Pop-Georgievski, O., Kubies, D. and Vollrath, F. 2016. Silk fibroin gelation via non-solvent induced phase separation. Biomater. Sci.

Kim, D. H., Viventi, J., Amsden, J. J., Xiao, J., Vigeland, L., Kim, Y. S., Blanco, J. A., Panilaitis, B., Frechette, E. S., Contreras, D., Kaplan, D. L., Omenetto, F. G., Huang, Y., Hwang, K. C., 
Hydrogels: Design, Synthesis \& Application in Drug Delivery \& Regenerative Medicine. Edited by Thakur Raghu Raj Singh, Garry Laverty and Ryan Donnelly 2017 SCIENCE PUBLISHERS (An Imprint of CRC Press/ Taylor \& Francis Group)

Zakin, M. R., Litt, B. and Rogers, J. A. 2010. Dissolvable films of silk fibroin for ultrathin conformal bio-integrated electronics. Nat. Mater. 9: 511-517.

Kim, U. J., Park, J., Li, C., Jin, H. J., Valluzzi, R. and Kaplan, D. L. 2004. Structure and properties of silk hydrogels. Biomacromolecules 5: 786-792.

Kluge, J. A., Rabotyagova, O., Leisk, G. G. and Kaplan, D. L. 2008. Spider silks and their applications. Trends Biotechnol. 26: 244-251.

Kojic, N., Panzer, M. J., Leisk, G. G., Raja, W. K., Kojicd, M. and Kaplan, D. L. 2012. Ion electrodiffusion governs silk electrogelation. Soft Matter 8: 6897-6905.

Lammel, A., Schwab, M., Hofer, M., Winter, G. and Scheibel, T. 2011. Recombinant spider silk particles as drug delivery vehicles. Biomaterials 32: 2233-2240.

Leisk, G. G., Lo, T. J., Yucel, T., Lu, Q. and Kaplan, D. L. 2010. Electrogelation for protein adhesives. Adv. Mater. 22: 711-715.

Li, M., Ogiso, M. and Minoura, N. 2003. Enzymatic degradation behavior of porous silk fibroin sheets. Biomaterials 24: 357-365.

Lovett, M. L., Wang, X., Yucel, T., York, L., Keirstead, M., Haggerty, L. and Kaplan, D. L. 2015. Silk hydrogels for sustained ocular delivery of anti-vascular endothelial growth factor (antiVEGF) therapeutics. Eur. J. Pharm. Biopharm. 95: 271-278.

Lu, Q., Huang, Y., Li, M., Zuo, B., Lu, S., Wang, J., Zhu, H. and Kaplan, D. L. 2011. Silk fibroin electrogelation mechanisms. Acta Biomater. 7: 2394-2400. 
Hydrogels: Design, Synthesis \& Application in Drug Delivery \& Regenerative Medicine. Edited by Thakur Raghu Raj Singh, Garry Laverty and Ryan Donnelly 2017 SCIENCE PUBLISHERS (An Imprint of CRC Press/ Taylor \& Francis Group)

Lu, Q., Zhu, H., Zhang, C., Zhang, F., Zhang, B. and Kaplan, D. L. 2012. Silk self-assembly mechanisms and control from thermodynamics to kinetics. Biomacromolecules 13: 826-832.

Lubec, G., Holbaubek, J., Feldl, C., Lucec, B. and Strouhal, E. 1993. Use of silk in acient Egypt. Nature 362: 25 .

Marsh, R. E., Corey, R. B. and Pauling, L. 1955. An investigation of the structure of silk fibroin. Biochem. Biophys. Acta 16: 1-34.

Matsumoto, A., Chen, J., Collette, A. L., Kim, U. J., Altman, G. H., Cebe, P. and Kaplan, D. L. 2006. Mechanisms of silk fibroin sol-gel transitions. J. Phys. Chem. B 110: 21630-21638.

Meinel, L., Hofmann, S., Karageorgiou, V., Kirker-Head, C., McCool, J., Gronowicz, G., Zichner, L., Langer, R., Vunjak-Novakovic, G. and Kaplan, D. L. 2005. The inflammatory responses to silk films in vitro and in vivo. Biomaterials 26: 147-155.

Min, S., Nakamura, T., Teramoto, A. and Abe, K. 1998. Preparation and characterization of crosslinked porous silk fibroin gel. Fiber 54: 85-92.

Numata, K., Cebe, P. and Kaplan, D. L. 2010. Mechanism of enzymatic degradation of beta-sheet crystals. Biomaterials 31: 2926-2933.

Omenetto, F. G. and Kaplan, D. L. 2008. A new route for silk. Nat. Photonics 2: 641-643.

Omenetto, F. G. and Kaplan, D. L. 2010. New opportunities for an ancient material. Science 329: 528-531. 
Hydrogels: Design, Synthesis \& Application in Drug Delivery \& Regenerative Medicine. Edited by Thakur Raghu Raj Singh, Garry Laverty and Ryan Donnelly 2017 SCIENCE PUBLISHERS (An Imprint of CRC Press/ Taylor \& Francis Group)

Partlow, B. P., Hanna, C. W., Rnjak-Kovacina, J., Moreau, J. E., Applegate, M. B., Burke, K. A., Marelli, B., Mitropoulos, A. N., Omenetto, F. G. and Kaplan, D. L. 2014. Highly tunable elastomeric silk biomaterials. Adv. Funct. Mater. 24: 4615-4624.

Porter, D., Guan, J. and Vollrath, F. 2013. Spider silk: super material or thin fibre? Adv. Mater. 25: $1275-1279$.

Price, R., Poursaid, A. and Ghandehari, H. 2014. Controlled release from recombinant polymers. J. Control. Release 190: 304-313.

Pritchard, E. M., Dennis, P. B., Omenetto, F. G., Naik, R. R. and Kaplan, D. L. 2012. Physical and chemical aspects of stabilization of compounds in silk. Biopolymers 97: 479-498.

Ribeiro, M., de Moraes, M. A., Beppu, M. M., Monteiro, F. J. and Ferraz, M. P. 2014. The role of dialysis and freezing on structural conformation, thermal properties and morphology of silk fibroin hydrogels. Biomatter. 4: e28536.

Rnjak-Kovacina, J. and Kaplan, D. L. 2013. Multifunctional silk-tropoelastin biomaterial systems. Israel J. Chem. 53: 777-786.

Rockwood, D. N., Preda, R. C., Yucel, T., Wang, X., Lovett, M. L. and Kaplan, D. L. 2011. Materials fabrication from Bombyx mori silk fibroin. Nat. Protoc. 6: 1612-1631.

Samal, S. K., Kaplan, D. L. and Chiellini, E. 2013. Ultrasound sonication effects on silk fibroin protein. Macromol. Mater. Eng. 298: 1201-1208. 
Hydrogels: Design, Synthesis \& Application in Drug Delivery \& Regenerative Medicine. Edited by Thakur Raghu Raj Singh, Garry Laverty and Ryan Donnelly 2017 SCIENCE PUBLISHERS (An Imprint of CRC Press/ Taylor \& Francis Group)

Schacht, K., Jungst, T., Schweinlin, M., Ewald, A., Groll, J. and Scheibel, T. 2015. Biofabrication of cell-loaded 3D spider silk constructs. Angew. Chem. Int. Ed. Engl. 54: 2816-2820.

Scheibel, T. 2004. Spider silks: recombinant synthesis, assembly, spinning, and engineering of synthetic proteins. Microb. Cell Fact. 3: 14.

Seib, F. P., Herklotz, M., Burke, K. A., Maitz, M. F., Werner, C. and Kaplan, D. L. 2014. Multifunctional silk-heparin biomaterials for vascular tissue engineering applications. Biomaterials 35: 83-91.

Seib, F. P., Jones, G. T., Rnjak-Kovacina, J., Lin, Y. and Kaplan, D. L. 2013. pH-dependent anticancer drug release from silk nanoparticles. Adv. Healthc. Mater. 2: 1606-1611.

Seib, F. P. and Kaplan, D. L. 2013. Silk for drug delivery applications: opportunities and challenges. Israel J. Chem. 53: 756-766.

Seib, F. P., Maitz, M. F., Hu, X., Werner, C. and Kaplan, D. L. 2012. Impact of processing parameters on the haemocompatibility of Bombyx mori silk films. Biomaterials 33: 1017-1023.

Seib, F. P., Pritchard, E. M. and Kaplan, D. L. 2013. Self-assembling doxorubicin silk hydrogels for the focal treatment of primary breast cancer. Adv. Funct. Mater. 23: 58-65.

Sponner, A., Schlott, B., Vollrath, F., Unger, E., Grosse, F. and Weisshart, K. 2005.

Characterization of the protein components of Nephila clavipes dragline silk. Biochemistry 44: $4727-4736$. 
Hydrogels: Design, Synthesis \& Application in Drug Delivery \& Regenerative Medicine. Edited by Thakur Raghu Raj Singh, Garry Laverty and Ryan Donnelly 2017 SCIENCE PUBLISHERS (An Imprint of CRC Press/ Taylor \& Francis Group)

Suntivich, R., Drachuk, I., Calabrese, R., Kaplan, D. L. and Tsukruk, V. V. 2014. Inkjet printing of silk nest arrays for cell hosting. Biomacromolecules 15: 1428-1435.

Tanaka, K., Kajiyama, N., Ishikura, K., Waga, S., Kikuchi, A., Ohtomo, K., Takagi, T. and Mizuno, S. 1999. Determination of the site of disulfide linkage between heavy and light chains of silk fibroin produced by Bombyx mori. Biochim. Biophys. Acta 1432: 92-103.

Tang-Schomer, M. D., White, J. D., Tien, L. W., Schmitt, L. I., Valentin, T. M., Graziano, D. J., Hopkins, A. M., Omenetto, F. G., Haydon, P. G. and Kaplan, D. L. 2014. Bioengineered functional brain-like cortical tissue. Proc. Natl. Acad. Sci. U S A 111: 13811-13816.

Thurber, A. E., Omenetto, F. G. and Kaplan, D. L. 2015. In vivo bioresponses to silk proteins. Biomaterials 71: 145-157.

Tokareva, O., Jacobsen, M., Buehler, M., Wong, J. and Kaplan, D. L. 2014. Structure-functionproperty-design interplay in biopolymers: spider silk. Acta Biomater. 10: 1612-1626.

Valluzzi, R., Gido, S. P., Muller, W. and Kaplan, D. L. 1999. Orientation of silk III at the airwater interface. Int. J. Biol. Macromol. 24: 237-242.

Vollrath, F. 1992. Spider webs and silks. Scientific American 266: 70-76.

Vollrath, F. and Porter, D. 2009. Silks as ancient models for modern polymers. Polymer 50: $5623-5632$.

Wang, X., Kluge, J. A., Leisk, G. G. and Kaplan, D. L. 2008. Sonication-induced gelation of silk fibroin for cell encapsulation. Biomaterials 29: 1054-1064. 
Hydrogels: Design, Synthesis \& Application in Drug Delivery \& Regenerative Medicine. Edited by Thakur Raghu Raj Singh, Garry Laverty and Ryan Donnelly 2017 SCIENCE PUBLISHERS (An Imprint of CRC Press/ Taylor \& Francis Group)

Wang, Y., Rudym, D. D., Walsh, A., Abrahamsen, L., Kim, H. J., Kim, H. S., Kirker-Head, C. and Kaplan, D. L. 2008. In vivo degradation of three-dimensional silk fibroin scaffolds.

Biomaterials 29: 3415-3428.

Werner, V. and Meinel, L. 2015. From silk spinning in insects and spiders to advanced silk fibroin drug delivery systems. Eur. J. Pharm. Biopharm. 97: 392-399.

Williams, D. F. 2008. On the mechanisms of biocompatibility. Biomaterials 29: 2941-2953.

Wray, L. S., Hu, X., Gallego, J., Georgakoudi, I., Omenetto, F. G., Schmidt, D. and Kaplan, D. L. 2011. Effect of processing on silk-based biomaterials: reproducibility and biocompatibility. J. Biomed. Mater. Res. B Appl. Biomater. 99: 89-101.

Xia, X. X., Qian, Z. G., Ki, C. S., Park, Y. H., Kaplan, D. L. and Lee, S. Y. 2010. Native-sized recombinant spider silk protein produced in metabolically engineered Escherichia coli results in a strong fiber. Proc. Natl. Acad. Sci. U S A 107: 14059-14063.

Xu, G., Gong, L., Yang, Z. and Liu, X. Y. 2014. What makes spider silk fibers so strong? From molecular-crystallite network to hierarchical network structures. Soft Matter 10: 2116-2123.

Yamaguchi, K., Kikuchi, Y., Takagi, T., Kikuchi, A., Oyama, F., Shimura, K. and Mizuno, S. 1989. Primary structure of the silk fibroin light chain determined by cDNA sequencing and peptide analysis. J. Mol. Biol. 210: 127-139.

Yodmuang, S., McNamara, S. L., Nover, A. B., Mandal, B. B., Agarwal, M., Kelly, T. A., Chao, P. H., Hung, C., Kaplan, D. L. and Vunjak-Novakovic, G. 2015. Silk microfiber-reinforced silk hydrogel composites for functional cartilage tissue repair. Acta Biomater. 11: 27-36. 
Hydrogels: Design, Synthesis \& Application in Drug Delivery \& Regenerative Medicine. Edited by Thakur Raghu Raj Singh, Garry Laverty and Ryan Donnelly 2017 SCIENCE PUBLISHERS (An Imprint of CRC Press/ Taylor \& Francis Group)

Yucel, T., Cebe, P. and Kaplan, D. L. 2009. Vortex-induced injectable silk fibroin hydrogels.

Biophys. J. 97: 2044-2050.

Yucel, T., Lovett, M. L. and Kaplan, D. L. 2014. Silk-based biomaterials for sustained drug delivery. J. Control. Release 190: 381-397.

Zeplin, P. H., Maksimovikj, N. C., Jordan, M. C., Nickel, J., Lang, G., Leimer, A. H., Römer, L. and Scheibel, T. 2014. Spider silk coatings as a bioshield to reduce periprosthetic fibrous capsule formation. Adv. Funct. Mater. 24: 2658-2666.

Zhao, Z., Li, Y. and Xie, M. B. 2015. Silk fibroin-based nanoparticles for drug delivery. Int. J. Mol. Sci. 16: 4880-4903.

Zhou, C. Z., Confalonieri, F., Jacquet, M., Perasso, R., Li, Z. G. and Janin, J. 2001. Silk fibroin: structural implications of a remarkable amino acid sequence. Proteins 44: 119-122.

Zhou, C. Z., Confalonieri, F., Medina, N., Zivanovic, Y., Esnault, C., Yang, T., Jacquet, M., Janin, J., Duguet, M., Perasso, R. and Li, Z. G. 2000. Fine organization of Bombyx mori fibroin heavy chain gene. Nucleic Acids Res. 28: 2413-2419. 